\title{
Crystal structure of dichlorobis(3,5-dimethylisoxazolato)palladium(II), $\mathrm{PdCl}_{2}\left(\mathrm{C}_{5} \mathrm{H}_{7} \mathrm{NO}\right)_{2}$
}

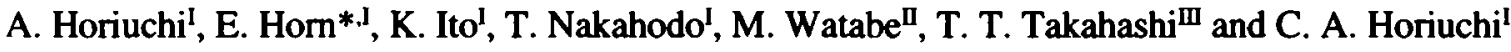 \\ I Rikkyo University, Department of Chemistry, 3-34-1 Nishi-Ikebukuro, Tosima-ku, Tokyo 171-8501, Japan \\ II Kogakuin University, Department of Applied Chemistry, 2665-1 Nakanochou, Hachioji, Tokyo 192-0001, Japan \\ III Jikei University, School of Medicine, Department of Chemistry, Kokuryo, Chofu, Tokyo 182-8570, Japan
}

Received October 19, 2004, accepted and available on-line January 12, 2005; CCDC no. 1267/1411

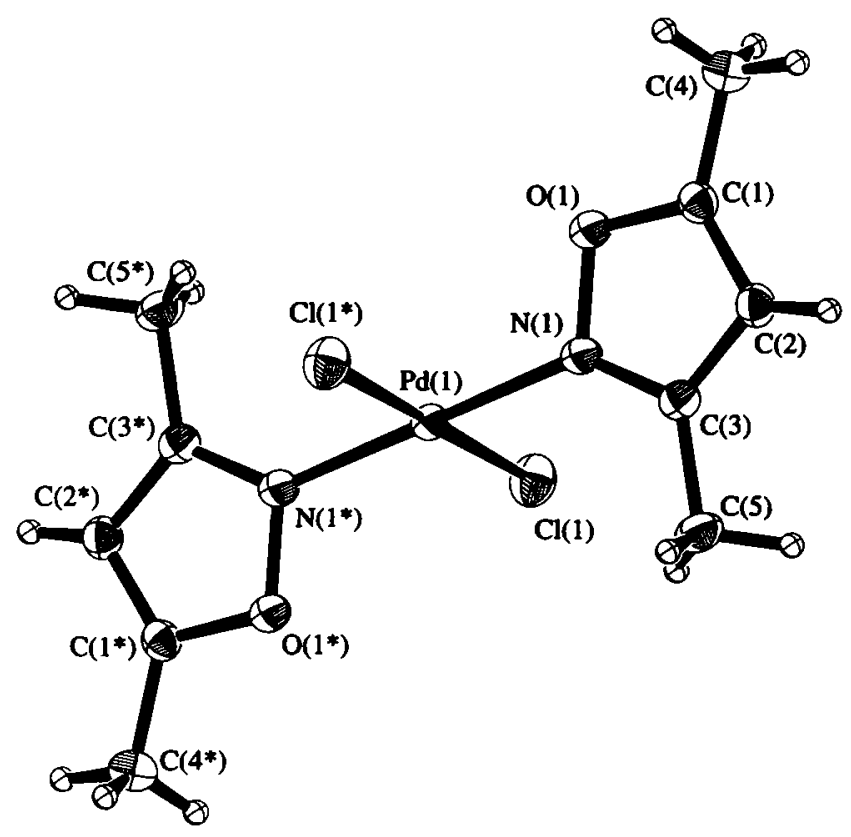

Abstract

$\mathrm{C}_{10} \mathrm{H}_{14} \mathrm{Cl}_{2} \mathrm{~N}_{2} \mathrm{O}_{2} \mathrm{Pd}$, triclinic, $P \overline{\mathrm{I}}$ (no. 2), $a=7.543$ (2) $\AA$,

$b=8.629(3) \AA, c=6.161(2) \AA, \alpha=109.38(2)^{\circ}$,

$\beta=108.03(2)^{\circ}, \gamma=101.89(3)^{\circ}, V=337.8 \AA^{3}, Z=1$,

$R_{\mathrm{gt}}(F)=0.032, w R_{\mathrm{obs}}(F)=0.036, T=296 \mathrm{~K}$.

\section{Source of material}

The Pd complex was prepared by mixing a two molar excess of 3,5-dimethyl-isoxazole and $\mathrm{PdCl}_{2}$ in distilled water at $300 \mathrm{~K}$ for $24 \mathrm{~h}$ [1]. Transparent yellow crystals of the product were obtained by slow recrystallization from acetone at room temperature. The crystals decompose in the range $220-225^{\circ} \mathrm{C}$.

\section{Experimental details}

In the final refinement all non-hydrogen atoms were modelled anisotropically using teXsan [2] and absorption corrected data [3]. The coordinates of the ring hydrogen atom $(\mathrm{H} 1)$ were refined, while the methyl hydrogen atoms were refined as two rigid groups.

\section{Discussion}

The discovery of the effects of cis-platinum has attracted a significant attention to coordination chemistry in search for complexes with medicinal potential. This preparative and structural study

\footnotetext{
* Correspondence author (e-mail: ehorn_chem@grp.rikkyo.ne.jp)
}

has been undertaken due to the potential bio-activity of palladium and platinum isoxazole complexes [4,5]. It is of particular interest that the complexes exhibit a higher bio-activity than the respective parent isoxazole derivatives alone [4-6].

This report unambiguously characterizes the $\mathrm{Pd}$ (II) complex with two coordinated chlorine atoms and two isoxazole ligands. The structure (40\% probability ellipsoids) shows the $\mathrm{Cl}, \mathrm{Cl}^{*}, \mathrm{~N} 1$, $\mathrm{N} 1 *$ and $\mathrm{Pdl}$ atoms in the same plane, as required by symmetry constraints. While the dihedral angle between the two leastsquare planes defined by the atoms $\mathrm{Pd} 1-\mathrm{Cl} 1-\mathrm{N} 1-\mathrm{Cl} 1 *-\mathrm{N} 1 *$ and O1-N1-C1-C2-C3 is $107.8(1)^{\circ}$. The molecule is located on the center of symmetry and the coordinates of the atoms with asterisks are equal to $-x,-y,-z$ with respect to the corresponding unique atom coordinates at $x, y, z$. The palladium atom is in a slightly distorted square planar environment with the respective coordination bond angles, Cl1-Pd1-N1 and $\mathrm{Cl}^{*}-\mathrm{Pd} 1-\mathrm{N} 1$, equal to $89.7(1)^{\circ}$ and $90.3(1)^{\circ}$. Two chlorine atoms coordinate to the metal center in a trans-configuration and with a bonding distance $d(\mathrm{Cl} 1-\mathrm{Pd} 1)=2.293(1) \AA$. The two trans mono-dentate isoxazole ligands coordinate through their nitrogen atoms, and the N1-Pd1 bonding distance is equal to $1.993(3) \AA$. All the other bond distances and bond angles are in the normal range.

Table 1. Data collection and handling.

\begin{tabular}{ll}
\hline Crystal: & $\begin{array}{l}\text { yellow, plate-like, } \\
\text { size } 0.050 \times 0.200 \times 0.250 \mathrm{~mm}\end{array}$ \\
& Mo $K_{\alpha}$ radiation $(0.7107 \AA)$ \\
Wavelength: & $35.21 \mathrm{~cm}^{-1}$ \\
$\mu:$ & Rigaku AFC7R, $\omega / 2 \theta$ \\
Diffractometer, scan mode: & $62^{\circ}$ \\
$2 \theta_{\text {max }}:$ & 1979,1857 \\
$N(h k l)_{\text {measared, }} N(h k l)_{\text {unique }}:$ & $I_{\text {obs }}>3 \sigma\left(I_{\text {obs }}\right), 1690$ \\
Criterion for $l_{\text {obs, }} N(h k l)_{\text {gt: }}:$ & 79 \\
$N($ param) & \\
Programs: & teXsan [2], ORTEP-II [7]
\end{tabular}

Table 2. Atomic coordinates and displacement parameters (in $\AA^{2}$ ).

\begin{tabular}{llllll}
\hline Atom & Site & $x$ & $y$ & $z$ & $U_{\text {iso }}$ \\
\hline H(1) & $2 i$ & 0.6570 & 0.3800 & 0.6930 & 0.059 \\
H(2) & $2 i$ & 0.7172 & 0.6216 & 1.1601 & 0.078 \\
H(3) & $2 i$ & 0.6490 & 0.4944 & 1.2701 & 0.078 \\
H(4) & $2 i$ & 0.8722 & 0.6023 & 1.3741 & 0.078 \\
H(5) & $2 i$ & 0.6292 & 0.0734 & 0.3402 & 0.091 \\
H(6) & $2 i$ & 0.8558 & 0.1102 & 0.4548 & 0.091 \\
H(7) & $2 i$ & 0.7100 & -0.0495 & 0.4464 & 0.091 \\
\hline
\end{tabular}


Table 3. Atomic coordinates and displacement parameters (in $\AA^{2}$ ).

\begin{tabular}{lllllllllll}
\hline Atom & Site & $x$ & $y$ & $z$ & $U_{11}$ & $U_{22}$ & $U_{33}$ & $U_{12}$ & $U_{13}$ & $U_{23}$ \\
\hline Pd(1) & $1 a$ & 0 & 0 & 0 & $0.0361(2)$ & $0.0338(2)$ & $0.0265(2)$ & $0.0139(2)$ & $0.0124(1)$ & $0.0127(1)$ \\
Cl(1) & $2 i$ & $0.6946(2)$ & $-0.2139(1)$ & $0.8222(2)$ & $0.0422(5)$ & $0.0458(5)$ & $0.0527(6)$ & $0.0079(4)$ & $0.0122(5)$ & $0.0212(5)$ \\
O(1) & $2 i$ & $0.8715(4)$ & $0.2993(3)$ & $1.1333(4)$ & $0.047(1)$ & $0.041(1)$ & $0.029(1)$ & $0.019(1)$ & $0.014(1)$ & $0.013(1)$ \\
N(1) & $2 i$ & $0.8687(5)$ & $0.1659(4)$ & $0.9260(5)$ & $0.043(2)$ & $0.037(2)$ & $0.029(1)$ & $0.016(1)$ & $0.014(1)$ & $0.012(1)$ \\
C(1) & $2 i$ & $0.7781(5)$ & $0.3983(5)$ & $1.0456(7)$ & $0.032(2)$ & $0.036(2)$ & $0.038(2)$ & $0.012(1)$ & $0.015(1)$ & $0.016(1)$ \\
C(2) & $2 i$ & $0.7195(6)$ & $0.3345(5)$ & $0.7938(7)$ & $0.038(2)$ & $0.042(2)$ & $0.038(2)$ & $0.017(2)$ & $0.015(2)$ & $0.020(2)$ \\
C(3) & $2 i$ & $0.7784(5)$ & $0.1869(5)$ & $0.7248(6)$ & $0.032(2)$ & $0.037(2)$ & $0.032(2)$ & $0.009(1)$ & $0.015(1)$ & $0.014(1)$ \\
C(4) & $2 i$ & $0.7594(7)$ & $0.5443(5)$ & $1.2375(8)$ & $0.053(2)$ & $0.042(2)$ & $0.044(2)$ & $0.020(2)$ & $0.021(2)$ & $0.012(2)$ \\
C(5) & $2 i$ & $0.7480(6)$ & $0.0632(6)$ & $0.4697(7)$ & $0.051(2)$ & $0.052(2)$ & $0.030(2)$ & $0.016(2)$ & $0.017(2)$ & $0.013(2)$ \\
\hline
\end{tabular}

Ackrowledgments. This work was supported by the Research Fund of the Tsukuba Advanced Research Alliance (TARA) project of the University of Tsukuba, and a Research Budget from Rikkyo University.

\section{References}

1. Horiuchi, A.; Itoh, K.; Nakahodo, T.; Watabe, M.; Hom, E.; Takahashi, T. T.; Horiuchi, C. A.: Synthesis and Properties of Palladium and Platinum Complexes with Isoxazole Derivatives as Ligands, $\mathbf{X X}^{\text {th }}$ European Colloquium on Heterocyclic Chemistry, Stockholm, Sweden 2002.

2. Molecular Structure Corporation: teXsan. Single Crystal Structure Analysis Software. Version 1.7. Molecular Structure Corporation, The Woodlands, Texas, USA 1995.
3. Walker, N.; Stuart, D.: An Empirical Method for Correcting Diffractometer Data for Absorption Effects. Acta Crystallogr. A39 (1983) 158-166.

4. Itoh, K.; Takahashi, S.; Sugiyama, T.; Takahashi, T. T.; Horiuchi, C. A.: Organometallic Chemistry directed towards Organic Synthesis, $11^{\text {th }}$ IUPAC Symposium on Organometallic Chemistry, Taipei, Taiwan 2001.

5. Zakharova, A.; Salyn, J. V.; Tatjianenko, J. V.; Mashkovsky, Y. S.; Ponticelli, G.: Inhibitory Activity of Palladium(II) and Platinum(II) Complexes with Isoxazole and its Derivatives. J. Inorg. Biochem. 15 (1981) 89-92.

6. Chunge, Y. J.; Kim, D. H.; Choi, K. Y.; Kim, B. H.: Isoxazole derivatives showing bioactivity. Korean J. Med. Chem. 5 (1995) 141-145.

7. Johnson, C. K.: ORTEP-II. Report ORNL-5138, Oak Ridge National Laboratory, Tennessee, USA 1976. 